Article

\title{
Durability Increase by Polyester Coating of Some Quaternary Copper-Based Alloys Parts
}

\author{
Anișoara Corăbieru ${ }^{1}$, Petrică Corăbieru ${ }^{2}$, Ștefan Velicu ${ }^{3}$, Ioana Arina Gherghescu ${ }^{4}$ and \\ Mirela Gabriela Sohaciu ${ }^{4, *}$ \\ 1 Faculty of Materials Science and Engineering, Technical University "Gheorghe Asachi", 700050 Iași, Romania; \\ acorabieru@yahoo.com \\ 2 SC Procomimpex SRL, 700543 Iași, Romania; pcorabieru@yahoo.com \\ 3 Faculty of Industrial Engineering and Robotics, Politehnica University of Bucharest, 313 Splaiul \\ Independenței, 060042 Bucharest, Romania; velstefan@hotmail.com \\ 4 Faculty of Materials Science and Engineering, Politehnica University of Bucharest, 313 Splaiul \\ Independentei, 060042 Bucharest, Romania; gherghescu_ioana@yahoo.com \\ * Correspondence: mirela.sohaciu@upb.ro; Tel.: +40-722-458-569
}

Received: 9 March 2020; Accepted: 17 April 2020; Published: 24 April 2020

\begin{abstract}
The need to increase the reliability of the metal parts and the assessment of the cost-quality parameters of a matrix require big manufacturers to find new technological solutions focused on the following aspects: thin layer deposits, metallic coatings, use of bimetals, and multilayer materials. The coating of the copper-based quaternary alloys with carbon graphite impregnated polyester aims to improve the performance of the metal parts used in the aeronautics, automotive, and railway industries. The goal is to achieve the following objectives: to reduce the rate of premature failure, to reduce the maintenance and service costs, and to increase the service life (the competitiveness of the manufacturing companies is positively influenced by the latter). This paper studies the operating behavior of some copper-based quaternary alloys coated with carbon graphite-impregnated polyester. The influence of the carbon graphite coating is studied in terms of operating behavior, especially aiming to assess the intensity of the wear and the intensity of the accumulated wear. On the whole, proper wear behavior entails the possibility of obtaining an increase in the service life.
\end{abstract}

Keywords: sustainable product design; polyester; graphite; copper-based quaternary alloys; wear; polymerization

\section{Introduction}

In this paper, the sustainability of a product is regarded not as a final state, but as a process that can be continuously improved. The development of this technology in order to extend the sustainability by changing the characteristics of the products has the following effects: increasing the safety and the operating life of these parts, reducing the maintenance interventions, and obtaining environmentally-friendly products (the metal being protected from oxidation). These decisions are in accordance with the recommendations of the European Parliament concerning the analysis of the products' life cycles and ensure the fabrication of some competitive products.

Due to the need to preserve the cost and quality parameters of the matrix, the aeronautics, automotive, and railway industries use metal parts coated with wear-resistant thin layers $[1,2]$. Generally, the thin layers serve the following roles: to increase the wear resistance; to increase the corrosion resistance; to increase the resistance to backlashes and heat variations; to reduce the friction force by improving the lubrication; and to increase the resistance to oxidation $[3,4]$. The coating of the copper-based quaternary alloys of CuNiAlSi type $(\mathrm{Ni}=3.80-4.10 \% ; \mathrm{Al}=1.20-1.50 \% ; \mathrm{Si}=1.00-1.20 \%$ ) 
with thin layers of carbon graphite-impregnated polyester is intended to improve the lubrication and to decrease the friction consequences with a direct effect on the operating durability of metal parts such as rollers, drums, wheels, pinions, toothed gears, rings, transmission cylinders, shoes, clutches, and discs $[5,6]$. The polyester resin impregnated with carbon graphite ensures an important increase of the oxidation resistance with a direct effect on the extension of the life span of the metal part and provides proper lubrication and a reduction of the frictional force. Polyesters are a category of polymers that contain the ester functional group in their main chain. Polyethylene terephthalate (PET), sum formula: $\mathrm{H}-\left[\mathrm{C}_{10} \mathrm{H}_{8} \mathrm{O}_{4}\right]-\mathrm{n}=60-120 \mathrm{OH}$ was used. This material was chosen for its outstanding mechanical, chemical and eco-friendly properties (low emissions to the environment during production and processing, low toxicity). The chosen copper-based CuNiAlSi quaternary alloy, treated by salt bath hardening + ageing, has a high hardness. The coat of polyester resin provides a set of properties that allow a longer operating life, without faults and downtimes (the effects of the friction and low wear are cumulated).

\section{Materials and Methods}

Experiments meant to study the wear process under similar conditions to the operational ones were performed. The experimental clutches are of the roller-roller type, with a diameter of $d_{1}=d_{2}=$ $50.00 \mathrm{~mm}$ and roller thickness $\mathrm{B}=10 \mathrm{~mm}$. The rollers are made of copper-based quaternary alloys CuNiAlSi, coated with polyester resin in which a percentage of $5 \%$ carbon graphite was incorporated. Before being coated, the surfaces were polished and subjected to a cleaning-degreasing operation, avoiding the silicate-based solutions [7]. The polymerization-fixation reactions occur during the treatment of the coated surfaces. The main technological parameters of the polymerization-fixation treatment are: $\mathrm{T}_{\text {heating }}=200^{\circ} \mathrm{C}$, tholding $=20 \mathrm{~min}$. Figure 1 shows the following elements: diagram and parameters of the salt bath hardening; diagram and parameters of the ageing heat treatment.

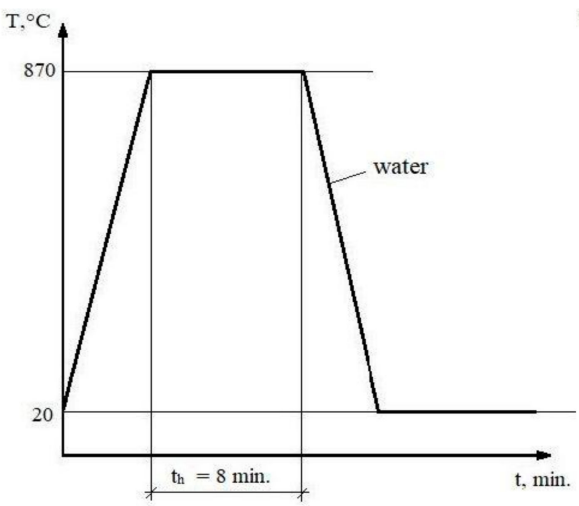

(a)

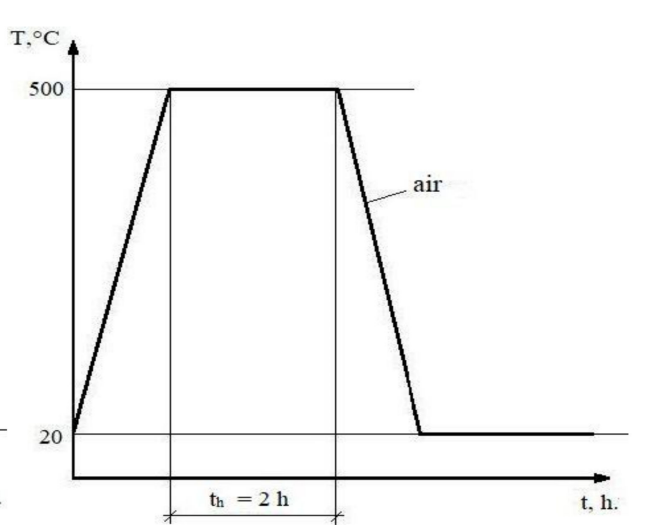

(b)

Figure 1. Salt bath hardening and ageing, used for studying the wear behavior of a roller type test specimen made of CuNiAlSi quaternary alloy: (a) diagram and parameters of salt bath hardening; (b) diagram and parameters of ageing heat treatment.

Figure 2 shows the diagram and parameters of the polymerization-fixation treatment of a roller-type CuNiAlSi test specimen previously coated with 5\% carbon graphite impregnated polyester.

The technological flow for coating the CuNiAlSi quaternary alloy test specimens is shown in Figure 3, while the technological parameters are shown in Table 1. 


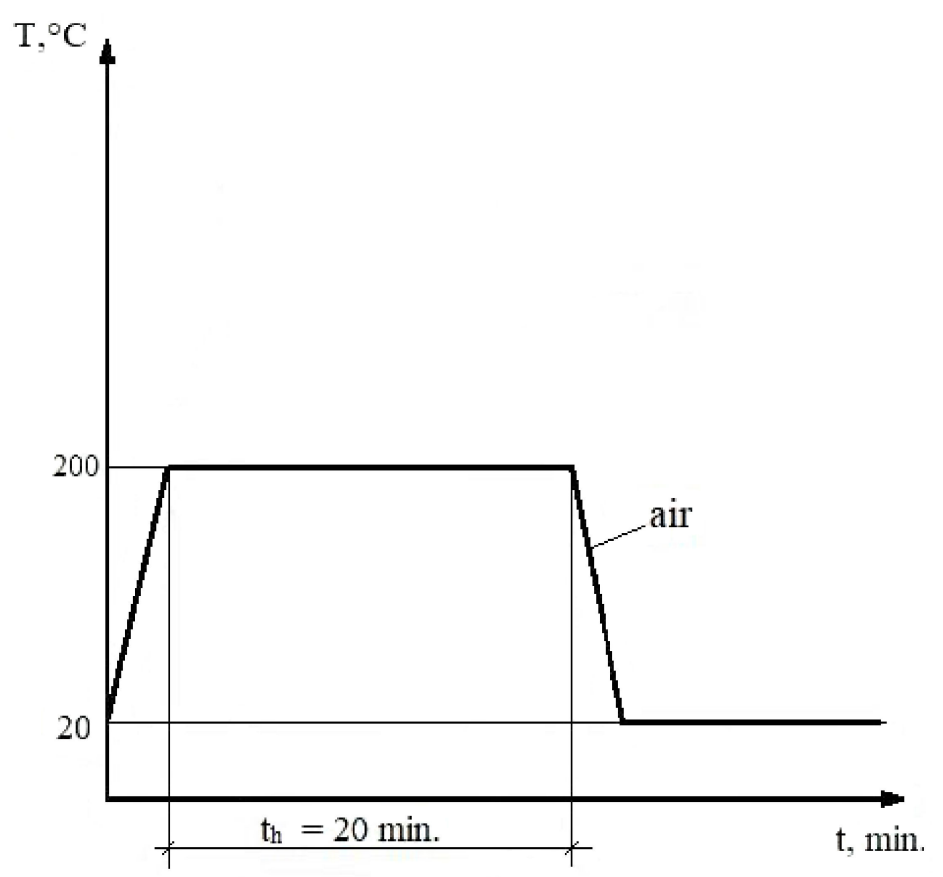

Figure 2. Diagram and parameters of the polymerization-fixation treatment of a roller-type CuNiAlSi test specimen previously coated with $5 \%$ carbon graphite impregnated polyester.

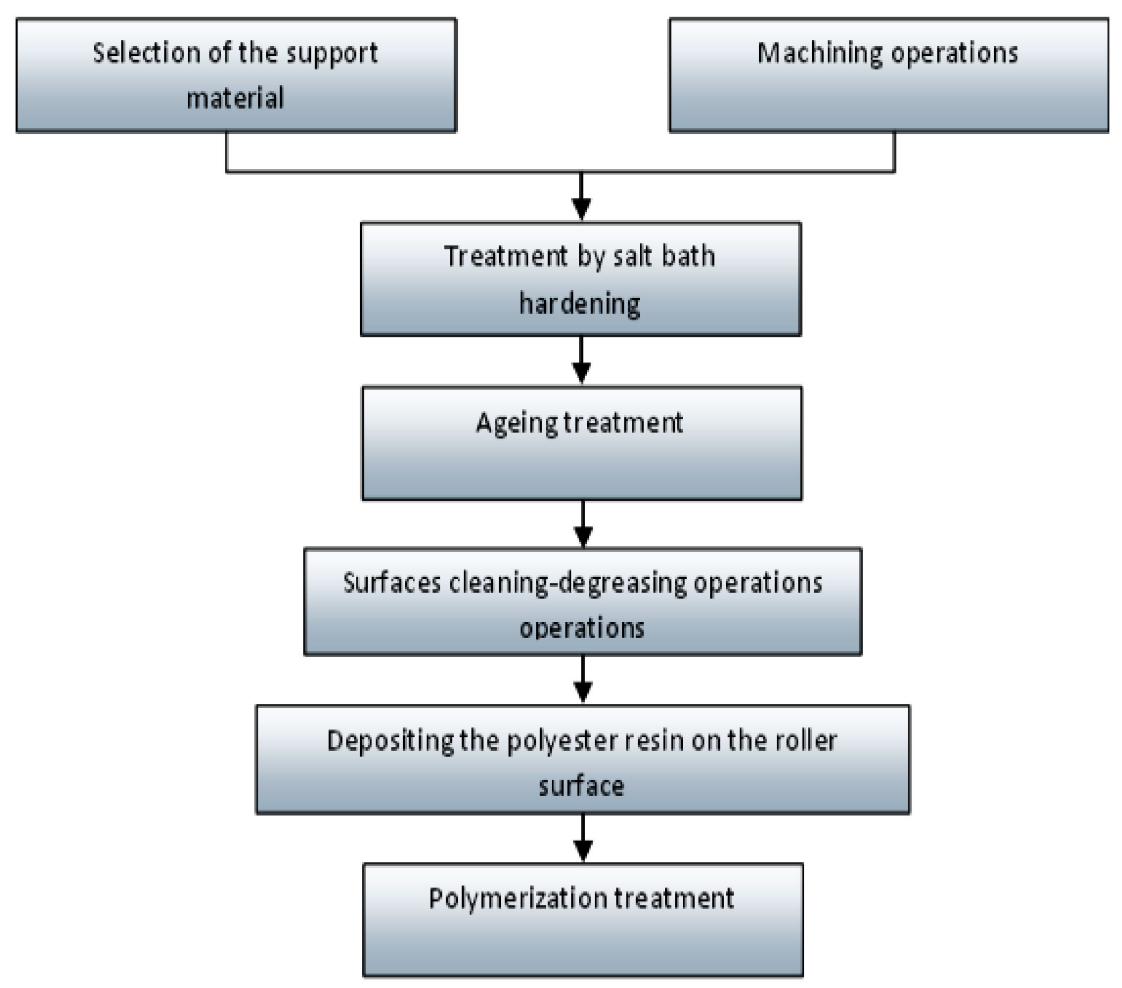

Figure 3. Technological flow for depositing the polyester resins on the surface of the quaternary alloy rollers.

The polyester coated rollers made of the CuNiAlSi quaternary alloy, obtained after the polymerization-fixation treatment, are ground before the experimental tests; the average thickness of the polyester coat is $100 \mu \mathrm{m}$. Figure 4 shows the microstructure of the quaternary alloy coated with polyester after the polymerization-fixation treatment. 
Table 1. Preparation of quaternary alloy rollers for coating with polyester resin.

\begin{tabular}{|c|c|c|}
\hline No & Technological Operation & Parameters \\
\hline 1 & $\begin{array}{l}\text { Machining operations, } \varnothing 50 \mathrm{~mm} \\
\text { bar made of CuNiAlSi }\end{array}$ & $\begin{array}{l}\mathrm{Ni}=3.80-4.10 \% ; \mathrm{Al}=1.20-1.50 \% ; \mathrm{Si}=1.00-1.20 \% \text {; Roller size: } \\
\text { diameter } \varnothing=50 \mathrm{~mm} \text {; roller thickness } \mathrm{B}=10 \mathrm{~mm} \text {; hole } \\
\text { diameter } \varnothing=10 \mathrm{~mm} \text {. }\end{array}$ \\
\hline 2 & Salt bath hardening & $\begin{array}{l}\mathrm{T}=870{ }^{\circ} \mathrm{C} ; \mathrm{t}_{\text {holding }}=8 \mathrm{~min} . ; \text { water cooling. Effect: removing } \\
\text { the state of strain hardening and restoring the initial plasticity } \\
\text { properties. }\end{array}$ \\
\hline 3 & Ageing treatment & $\begin{array}{l}\mathrm{T}=500{ }^{\circ} \mathrm{C} \text {; } \mathrm{t}_{\text {holding }}=2 \mathrm{~h} \text {; air cooling; Effect: heating in order } \\
\text { to pass the suprasaturated solid solution (metastable } \\
\text { structure) into an equilibrium state by precipitating } \\
\text { intermetallic compounds. } \\
\text { - mechanical cleaning; }\end{array}$ \\
\hline 4 & Cleaning-degreasing of surfaces & - polishing; \\
\hline 5 & $\begin{array}{l}\text { Depositing the polyester resin on } \\
\text { the roller surface }\end{array}$ & $\begin{array}{l}\text { - degreasing (avoiding the silicates based solutions). } \\
\text { - incorporation of } 5 \% \text { carbon graphite in the polyester resin; } \\
\text { - maintaining the uniformity of the deposited layer; } \\
\text { - average thickness of the deposited layer }=100 \mu \mathrm{m}\end{array}$ \\
\hline 6 & Polymerization treatment & $\begin{array}{l}\mathrm{T}=200^{\circ} \mathrm{C} ; \mathrm{t}_{\text {holding }}=20 \mathrm{~min} . ; \text { air cooling; } \\
\text { - creation of conditions for polymerization reactions }\end{array}$ \\
\hline
\end{tabular}

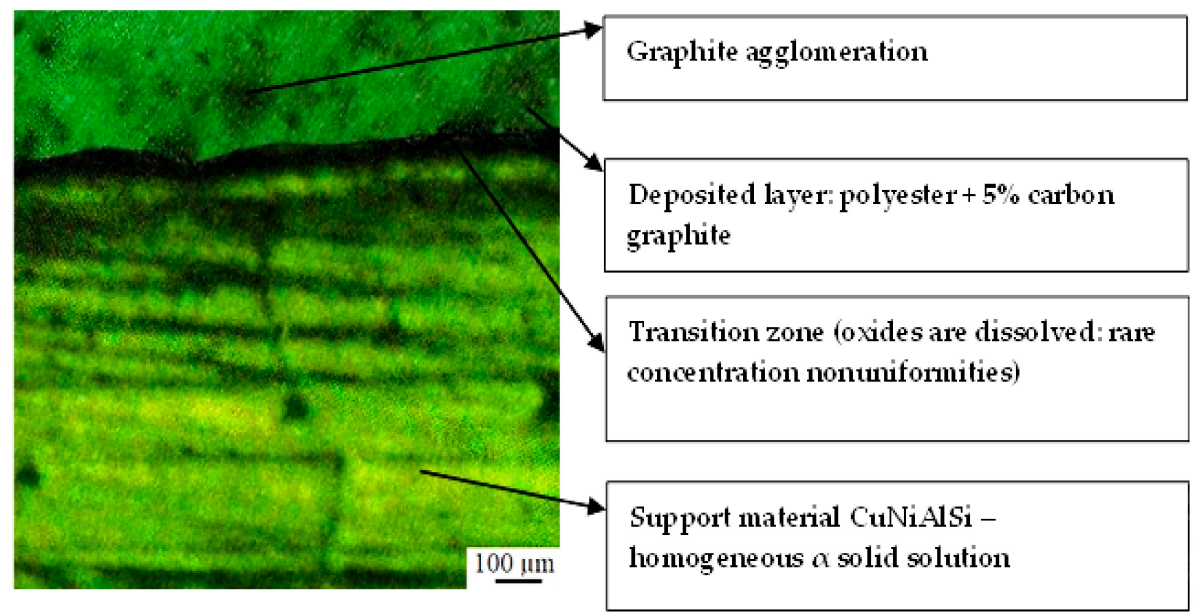

Figure 4. Microstructure of the quaternary alloy CuNiAlSi coated with polyester $(\times 100)$.

Table 2 shows the characteristics, symbols, and equations used during the assessment of the operational behavior of the CuNiAlSi alloys coated with polyester [8,9].

Table 2. Dimensions, symbols, and equations used during experiments.

\begin{tabular}{ccc}
\hline Characteristics & Symbol, UM & Values or Equations \\
\hline Diameter of rollers & $\mathrm{d}_{1}, \mathrm{~d}_{2}[\mathrm{~mm}]$ & $\mathrm{d}_{1}=50,00$ \\
Contact width & $\mathrm{B},[\mathrm{mm}]$ & $\mathrm{B}=10$ \\
Operating speed & $\mathrm{n}_{1}, \mathrm{n}_{2},[\mathrm{RPM}]$ & $\mathrm{n}_{1}=\mathrm{n}_{2}=200$ \\
Sliding & $\mathrm{S},[\%]$ & $S=\frac{n_{2} \cdot d_{2}-n_{1} \cdot d_{1}}{n_{1} \cdot d_{1}}$ \\
Normal load of the rollers & $\mathrm{Q},[\mathrm{N}]$ & $\mathrm{Q}=60$ \\
Friction time & $\mathrm{T},[\mathrm{s}]$ & - \\
Friction length & $\mathrm{L}_{\mathrm{f}},[\mathrm{mm}]$ & $L f=\frac{\pi \cdot \mathrm{d}_{1} \cdot n_{1} \cdot T}{60}$ \\
Thickness of the worn layer & $\mathrm{G}_{\mathrm{f}},[\mathrm{mm}]$ & $-\frac{G f}{L f}$ \\
Wear intensity & $\mathrm{I}_{\mathrm{m}},\left(\times 10^{-9}\right)$ & $I m=\frac{\mathrm{G} f}{L f}$
\end{tabular}


The experimental tests are aimed at studying the friction in the linear contact roller-roller clutches and on curved surfaces, using the experimental test stand which is presented in Figure 5 [8].

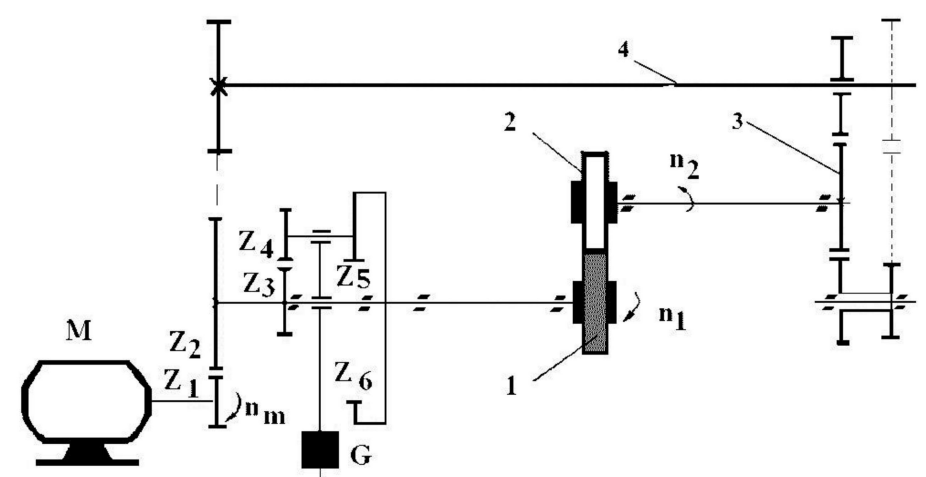

Figure 5. A functional diagram of the experimental stand for the wear resistance experiments: 1-roller 1 of the CuNiAlSi alloy coated with polyester; 2 -roller 2 of the heat-treated CuNiAlSi alloy; 3 - cogwheels gears that take over the movement of roller 2; 4-basic bar of the experimental stand; $\mathrm{M}$-electric drive motor; $\mathrm{n}_{\mathrm{m}}$-electric motor speed, rpm; $\mathrm{Z}_{1}, \mathrm{Z}_{2}, \mathrm{Z}_{3}, \mathrm{Z}_{4} \ldots$-gearboxes; $\mathrm{n}_{1}$-roller speed $1=200 \mathrm{rpm} ; \mathrm{n}_{2}$-roller speed $2=200 \mathrm{rpm}$.

The rotational movement is transmitted from the motor through the kinematic chains with cogwheel gears. The normal load on $\mathrm{Q}$ rollers is achieved by a mechanical system with screw and compression spring, being able to vary within the limits of $0-2000 \mathrm{~N}$. The value of the load $\mathrm{Q}$ can be read directly on the graduated scale attached to the compression spring. The diameters of the rollers range from 30 to $60 \mathrm{~mm}$ and the width is $10 \mathrm{~mm}$ (the rated load on the rollers was $Q=60 \mathrm{~N}$ during the experiments). The motor speed is $1450 \mathrm{rpm}$. The two roller-type test specimens rotate in the opposite direction; a pure rolling motion or rolling with a sliding motion, depending on the diameters of the test specimens, occur at their contact. The working speeds of the two test specimens are around $200 \mathrm{rpm}$. When the rollers have equal diameters, there is a sliding of $10 \%$ approximately. By changing the diameters of the two rollers, variable sliding ranging from 0 to $30 \%$ can be obtained. Figure 6 shows the wear diagram of the rolling pairs used in the experiments.

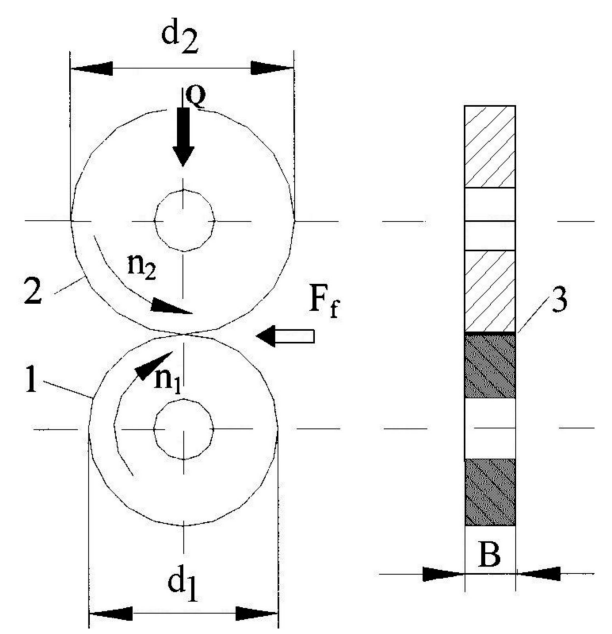

Figure 6. Roller wear scheme: 1-roller 1 made of CuNiAlSi alloy coated with polyester resin in which $5 \%$ carbon graphite was incorporated; 2 -roller 2 made of CuNiAlSi alloy treated by salt bath hardening + ageing; 3-contact surface between rollers; $\mathrm{Q}$-rated load on contact surface $=60 \mathrm{~N}$; $\mathrm{F}_{\mathrm{f}}$-friction force; $B$-rollers width $=10 \mathrm{~mm}$; $d_{1}$-diameter of roller $1=50 \mathrm{~mm}$; $\mathrm{d}_{2}$-diameter of roller $2=50 \mathrm{~mm}$; $\mathrm{n}_{1}$-rotational speed of the roller $1=200 \mathrm{rpm} ; \mathrm{n}_{2}$-rotational speed of the roller $2=200 \mathrm{rpm}$. 
The rated load on the contact surface is $\mathrm{Q}=60 \mathrm{~N}$ and ensures dry friction without relative sliding during the wear tests.

\section{Results}

The results of the dry friction experimental tests on rolling pairs are listed in Tables 3 and 4 . The rollers are made of CuNiAlSi alloys treated and coated with polyester. The tests at dry wear performed on the experimental tests stand lasted $\mathrm{T}=8 \mathrm{~h}$. The time between two measurements of the linear wear intensity is of $1 \mathrm{~h}, \Delta \mathrm{T}=3600$ seconds, respectively.

Table 3. Tests at dry wear on rolling pairs. Roller 1: CuNiAlSi alloy treated by salt hardening + ageing; Roller 2: CuNiAlSi alloy treated by salt hardening + ageing.

\begin{tabular}{cccccccccc}
\hline $\begin{array}{c}\text { Friction } \\
\text { time, } \mathbf{T}(\mathbf{h})\end{array}$ & $\begin{array}{c}\mathbf{d}_{\mathbf{1}} \\
(\mathbf{m m})\end{array}$ & $\begin{array}{c}\mathbf{d}_{\mathbf{2}} \\
(\mathbf{m m})\end{array}$ & $\mathbf{S} \mathbf{( \% )}$ & $\mathbf{Q} \mathbf{( N )}$ & $\mathbf{\Delta} \mathbf{T}(\mathbf{s})$ & $\mathbf{L}_{\mathbf{f}}(\mathbf{m})$ & $\begin{array}{c}\mathbf{G}_{\mathbf{f}} \\
(\mathbf{m m})\end{array}$ & $\begin{array}{c}\mathbf{I m} \\
\left(\times \mathbf{1 0}^{-\mathbf{9}}\right)\end{array}$ & $\begin{array}{c}\mathbf{I}_{\mathbf{m c}} \\
\left(\times \mathbf{1 0}^{-\mathbf{9}}\right)\end{array}$ \\
\hline 1 & 50.00 & 52.64 & 5.280 & 60 & 3600 & 1884.00 & 0.01 & 5.3078 & 5.3078 \\
2 & 49.98 & 52.61 & 5.262 & 60 & 3600 & 1883.24 & 0.01 & 5.3099 & 10.6177 \\
3 & 49.95 & 52.58 & 5.265 & 60 & 3600 & 1882.11 & 0.01 & 5.3131 & 15.9308 \\
4 & 49.92 & 52.54 & 5.248 & 60 & 3600 & 1880.98 & 0.02 & 10.6327 & 26.5635 \\
5 & 49.88 & 52.50 & 5.252 & 60 & 3600 & 1879.47 & 0.02 & 10.6412 & 37.247 \\
6 & 49.84 & 52.46 & 5.256 & 60 & 3600 & 1877.97 & 0.02 & 10.6497 & 47.8544 \\
7 & 49.80 & 52.42 & 5.261 & 60 & 3600 & 1876.46 & 0.02 & 10.6583 & 58.5127 \\
8 & 49.76 & 52.38 & 5.265 & 60 & 3600 & 1874.95 & 0.02 & 10.6669 & 69.1796 \\
\hline
\end{tabular}

Table 4. Tests of dry wear on rolling pairs. Roller 1: CuNiAlSi alloy coated with polyester; Roller 2: CuNiAlSi alloy treated by salt hardening + ageing.

\begin{tabular}{|c|c|c|c|c|c|c|c|c|c|}
\hline $\begin{array}{c}\text { Friction } \\
\text { Time, T (h) }\end{array}$ & $\underset{(\mathrm{mm})}{\mathrm{d}_{1}}$ & $\begin{array}{c}\mathrm{d}_{2} \\
(\mathrm{~mm})\end{array}$ & S (\%) & $Q(N)$ & $\Delta \mathrm{T}(\mathrm{s})$ & $\mathrm{L}_{\mathrm{f}}(\mathrm{m})$ & $\underset{(\mathrm{mm})}{\mathrm{G}_{\mathrm{f}}}$ & $\begin{array}{c}\operatorname{Im} \\
\left(\times 10^{-9}\right)\end{array}$ & $\begin{array}{c}I_{m c} \\
\left(\times 10^{-9}\right)\end{array}$ \\
\hline 1 & 50.00 & 52.64 & 5.280 & 60 & 3600 & 1884.00 & 0.01 & 5.3078 & 5.3078 \\
\hline 2 & 49.98 & 52.61 & 5.260 & 60 & 3600 & 1883.24 & 0.01 & 5.3099 & 10.6177 \\
\hline 3 & 49.96 & 52.58 & 5.240 & 60 & 3600 & 1882.49 & 0.01 & 5.3131 & 15.9298 \\
\hline 4 & 49.94 & 52.54 & 5.200 & 60 & 3600 & 1881.73 & 0.01 & 5.3142 & 21.2440 \\
\hline 5 & 49.92 & 52.50 & 5.160 & 60 & 3600 & 1880.98 & 0.01 & 5.3163 & 26.5603 \\
\hline 6 & 49.90 & 52.46 & 5.130 & 60 & 3600 & 1880.32 & 0.01 & 5.3182 & 31.8785 \\
\hline 7 & 49.88 & 52.41 & 5.070 & 60 & 3600 & 1879.47 & 0.01 & 5.306 & 37.1991 \\
\hline 8 & 49.86 & 52.36 & 5.010 & 60 & 3600 & 1878.72 & 0.02 & 10.6455 & 47.8446 \\
\hline
\end{tabular}

The diameter measurements before and after the dry wear test show the depth of the worn layer and the intensity of the wear. The contact pressure causes an elastic deformation of the alloy; the polyester layer follows this deformation and does not allow the contact between the two metallic materials. In order to highlight the improvement of the wear resistance by coating the copper-based quaternary alloys with polyester, tests were made on the following types of rolling pairs: treated alloy-treated alloy; treated alloy coated with polyester-treated alloy. The comparative analysis performed during the experiments highlighted the positive influence of the thin polyester layer.

The results of the experiments are presented in Figure 7 (the rolling clutch is treated roller - treated roller type) and Figure 8 (the rolling clutch is treated roller coated with polyester - treated roller type) which show the values of the actual wear intensity and the cumulated wear intensity.

The experimental results reveal that the test specimens made of CuNiAlSi alloy coated with polyester impregnated with $5 \%$ carbon graphite have a higher resistance to wear compared to the treated test specimens made of CuNiAlSi alloy. The cumulated wear intensity recorded after $\mathrm{T}=$ $8 \mathrm{~h}$ of testing on the experimental stand in the case of the test specimens made of CuNiAlSi alloys coated with polyester is of the order of $47.8446 \times 10^{-9}$, as compared to $69.17969 \times 10^{-9}$ in the case of the test specimens made of the CuNiAlSi alloy treated by salt bath hardening + ageing. These values indicate a decrease of the cumulated wear intensity by $30 \%$, approximately. The impregnation of the dry carbon graphite powder into the polyester, due to the lamellar structure of the graphite, improves the lubrication. A percentage of $5 \%$ carbon graphite provided adequate lubrication and contributed to 
the creation of a thermal barrier that insulated the CuNiAlSi alloy from a thermo-mechanical point of view and did not allow direct contact between the alloy roller-alloy roller.

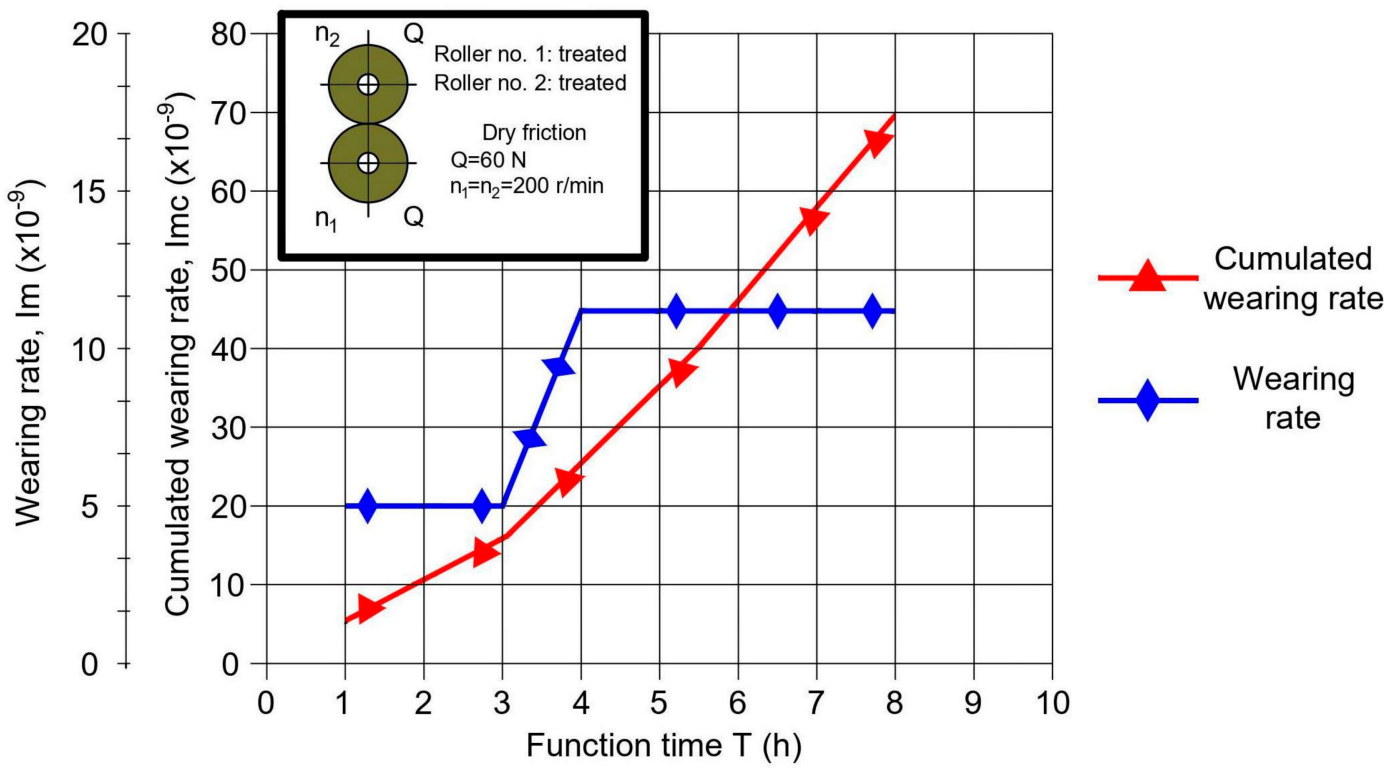

Figure 7. Wear intensity and cumulated wear intensity for Roller 1 (CuNiAlSi alloy treated by salt hardening + ageing)—dry friction without relative sliding.

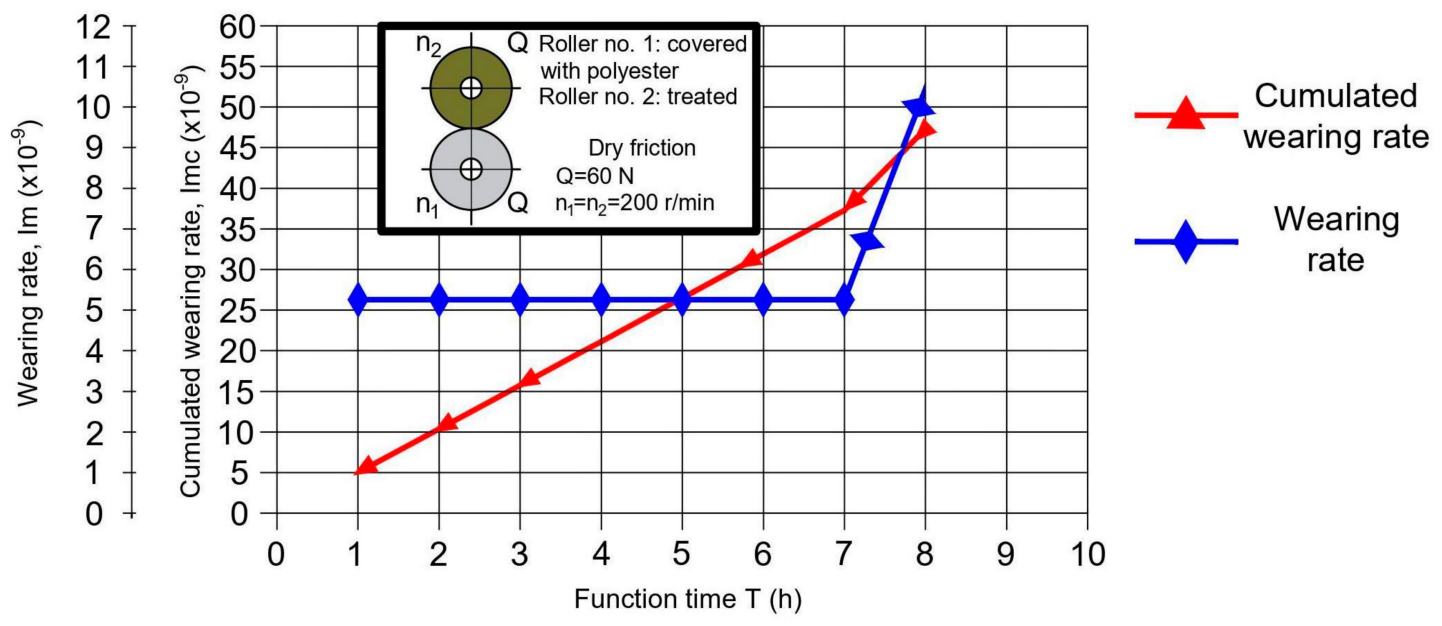

Figure 8. Wear intensity and cumulated wear intensity for Roller 1 (CuNiAlSi alloy coated with polyester)—dry friction without relative sliding.

\section{Discussion}

A comparative analysis was made between:

(1) The results of the experiments using a polyester resin impregnated with $10 \%$ carbon graphite as a dry powder [9];

(2) The results obtained during the experiments conducted for this paper, using polyester impregnated with $5 \%$ carbon graphite.

The results of the comparative analysis are shown in Table 5. 
Table 5. The comparative analysis of the experiment results.

\begin{tabular}{|c|c|c|c|c|}
\hline \multirow[b]{2}{*}{ No. } & \multirow{2}{*}{$\begin{array}{l}\text { Polyester Impregnated } \\
\text { with Carbon Graphite } \\
\qquad(\%)\end{array}$} & \multicolumn{2}{|c|}{ Cumulated Wear Intensity $\left(\times 10^{-9}\right)$} & \multirow{2}{*}{$\begin{array}{l}\text { Decrease of the } \\
\text { Cumulated Wear } \\
\text { Intensity, }(\%)\end{array}$} \\
\hline & & Roller/Roller & $\begin{array}{c}\text { Roller with } \\
\text { Polyester/Roller }\end{array}$ & \\
\hline 1 & 10 & 74.49 .9 & 47.8447 & 35 \\
\hline 2 & 5 & 69.1796 & 47.8446 & 30 \\
\hline
\end{tabular}

Analyzing data in Table 5 reveals that the graphite percentage impregnated in polyester resin has an important influence on improving lubrication and increasing the oxidation resistance by creating thermo-mechanical barriers. The increase of the percentage of carbon graphite impregnated in polyester from 5 to 10 [\%] entailed the decrease in the cumulated wear intensity to $35 \%$ (for $10 \%$ carbon graphite) as against $30 \%$ (for $5 \%$ carbon graphite). The percentage values of the carbon graphite impregnated in the form of dry powder should be kept within an optimal range of 5 to $15 \%$.

\section{Conclusions}

The polyester layer deposited through polymerization-fixation treatment has a positive influence on the quaternary alloys of CuNiAlSi type because it leads to the decrease of the cumulated wear intensity by about $35 \%$. The polyester impregnated with carbon graphite under the form of dry powder takes over the elastic deformations to which are submitted the metal parts made of the quaternary alloys during operation, directly contributing to the wear resistance improvement, to the friction intensity reduction by providing proper lubrication, to the increase of corrosion resistance, and to oxidation resistance by forming thermo-mechanical barriers.

The polyester layer ensures good adhesion and a negligible fragility, taking over some of the tensions generated by the contact stresses and prolonged shock during the service life of the gears and metal parts. The percentage values of carbon graphite impregnated in the form of dry powder should be within an optimal range of $5-15 \%$.

The effects of coating the metal parts with polyester layers are economically felt as follows: a decrease of the average rate of rejects by $5 \%$, and respectively, abatement by $400 \mathrm{ppm}$ of the loss of the layer's thickness; a decrease of premature failure by $10 \%$; and an increase of the service life by $10 \%$.

From an ecological point of view, the coating of the quaternary alloys with polyester does not raise particular problems in terms of exceeding the limit values of emission of the volatile organic compounds in the working atmosphere. The values are consistent with the requirements imposed by the European environmental directives. The metal parts coated with polyester can be considered green products. The good results obtained in the laboratory will also be confirmed at the industrial level.

Author Contributions: Conceptualization, A.C. and P.C.; methodology, S.V.; validation, S.V. and I.A.G.; formal analysis, M.G.S.; investigation, M.G.S.; writing-original draft preparation, P.C.; writing-review and editing, I.A.G. and M.G.S.; supervision, S.V. All authors have read and agreed to the published version of the manuscript.

Funding: This research received no external funding.

Acknowledgments: The research presented in this paper has been supported by: Romanian National Project CEEX, Ref nr.180/20.07.2006, "Technology for the manufacture of light automotive components (bearings, cylinders, axles, bushings etc.) made of bimetallic semi-finished products obtained from liquid phase".

Conflicts of Interest: The authors declare no conflicts of interest.

\section{References}

1. Predescu, C.; Berbecaru, A.C.; Coman, G.; Sohaciu, M.G.; Predescu, A.M.; Matei, E.; Dumitrescu, R.E.; Ciucă, S.; Gherghescu, I.A. Corrosion Resistance Evaluation of Some Stainless Steels Used in Manufacture of Hydraulic Turbine Runner Blades. Rev. Chim. Buchar. 2019, 70, 2491-2496. [CrossRef]

2. Dumitru, Z.; Stefan, V.; Petrica, C.; Anisoara, C.; Dragos, V.D. Tendencies and solutions regarding the development of the metallic products for auto-vehicles. Metal. Int. 2008, 13, 76-81. 
3. Bangert, H.; Eisenmenger-Sittner, C.; Bergauer, A. Deposition and structural properties of two-component metal coatings for tribological applications. Surf. Coat. Technol. 1996, 80, 162-170. [CrossRef]

4. Miyoshi, K. Durability Evaluation of Selected Solid Lubricating Films, NASA/TM-2001-210360. In Proceedings of the 13th International Conference on Wear of Materials, Vancouver, BC, Canada, 23-27 April 2001.

5. Belâi, V.A.; Starzhinskiy, V.Y.; Scherbakov, C.B. Metallo-Polimernâe Zubciatâe Peredaci; Nauchno-Tekhn Inform: Minsk, Belarus, 1981.

6. Hirata, A.; Igarashi, M.; Kaito, T. Study on solid lubricant properties of carbon onions produced by heat treatment of diamond clusters or particles. Tribol. Int 2004, 37, 899-905. [CrossRef]

7. Yukhno, T.P.; Vvedensky, Y.V.; Sentyurikhina, L.N. Low temperature investigations on frictional behavior and wear resistance of solid lubricant coatings. Tribol. Int. 2001, 34, 293-298. [CrossRef]

8. Corăbieru, A.; Corăbieru, P. Bimetallic light automotive parts obtained from liquid phase. In Proceedings of the Conference Excellence Research-A Way to Innovation, Brasov, Romania, 27-29 July 2008; Technical Publishing House: Bucharest, Romania, 2008.

9. Corăbieru, A.; Velicu, S.;; Corăbieru, P.; Vasilescu, D.D. Research on the use of plastics in order to increase the life of the product. Mater. Plast. 2014, 51, 176-179.

(C) 2020 by the authors. Licensee MDPI, Basel, Switzerland. This article is an open access article distributed under the terms and conditions of the Creative Commons Attribution (CC BY) license (http://creativecommons.org/licenses/by/4.0/). 